\title{
Propagación in vitro de Solanum dolichosepalum (Solanaceae)
}

\author{
In vitro Propagation of Solanum dolichosepalum (Solanaceae)
}

\author{
Camilo Andrés Cárdenas-Burgos ${ }^{\mathrm{a}^{*}}$ \\ José C. Pacheco-Maldonado ${ }^{\mathrm{b}}$ \\ André L. L. Vanzela ${ }^{c}$
}

Recepción: 19-ene-2016

Aceptación: 28-abr-2016

\begin{abstract}
Resumen
Se estableció un protocolo para micropropagación de Solanum dolichosepalum a partir de semillas desinfectadas con $\mathrm{NaOCl}$ y germinadas en MS/4. La multiplicación de microtallos se realizó por segmentos nodales, evaluando el efecto de la posición del segmento nodal, concentración de AIB y BA, concentración de sales MS en presencia de AIB, concentración de sales MS y sacarosa en presencia de carbón activado, diferentes medios de cultivo y concentración de carbón activado sobre la longitud total de microtallos, promedio de yemas neoformadas, porcentaje de microtallos con callo basal y porcentaje de microtallos enraizados. Después de 20 días de cultivo en MS/4 el 100\% de las semillas cultivadas desarrollaron plántulas de apariencia normal. La multiplicación de microtallos fue exitosa en medio $\mathrm{H}$ con $2 \%$ de sacarosa suplementado con $0,02 \mathrm{mg} \mathrm{L}^{-1}$ de ANA y de BA; después de 30 días de subcultivo los microtallos desarrollados alcanzaron 4 $\mathrm{cm}$ de longitud, formaron 4 yemas axilares, el $3 \%$ formó callo basal y el 100\% presentó enraizamiento. La aclimatización de plántulas se realizó exitosamente en una mezcla de tierra, capote y arena $(3: 2: 1)$. Este protocolo forma parte de un programa de producción de material injertado de lulo de castilla para establecimiento de huertos comerciales.
\end{abstract}

Palabras clave: Callo basal, Enraizamiento, Lulo, Micropropagación, Solanáceas silvestres.

\begin{abstract}
A protocol for micropropagation of Solanum dolichosepalum was established from seeds disinfected with $\mathrm{NaOCl}$ and germinated in MS/4. Multiplication of microshoots was performed by nodal segments evaluating the effect of the nodal segment position, BA and IBA concentrations, MS salts concentration in presence of AIB, MS salts and sucrose concentration in the presence of activated charcoal, different culture media, and activated charcoal concentration on the total length of microshoots, average of newly formed buds, percentage of microshoots with basal callus and percentage of rooted microshoots. After 20 days of culture in MS/4 100\% of cultured seeds developed plantlets with normal appearance. Microshoots multiplication
\end{abstract}

\footnotetext{
aBiol. Estudiante Maestría en Ciencias Biológicas-UPTC. Laboratorio de Cultivo de Tejidos Vegetales BIOPLASMA-UPTC. Universidad Pedagógica y Tecnológica de Colombia, Sede Central, Tunja-Colombia.

*Autor de correspondencia: camilo.cardenas@uptc.edu.co

${ }^{b} \mathrm{PhD}$. Laboratorio de Cultivo de Tejidos Vegetales BIOPLASMA-UPTC. Escuela de Ciencias Biológicas, Facultad de Ciencias. Universidad Pedagógica y Tecnológica de Colombia, Sede Central, Tunja-Colombia.

${ }^{c}$ Prof. Dr. Laboratorio de Citogenética y Diversidad Vegetal. Departamento de Biología General, Centro de Ciencias Biológicas. Universidad Estadual de Londrina. Londrina 86057-970, Paraná, Brasil.
} 
was successful in medium $\mathrm{H}$ with $2 \%$ sucrose supplemented with $0,02 \mathrm{mg} \mathrm{L}^{-1} \mathrm{NAA}$ and BA; after 30 days of subculture, the developed microshoots reached $4 \mathrm{~cm}$ in length, formed four axillary buds, $3 \%$ formed basal callus and $100 \%$ developed roots. Plantlets acclimatization was successfully performed on a mixture of soil, mulch and sand $(3: 2: 1)$. This protocol is part of a program to produce grafted material of "Lulo de Castilla" for establishment of commercial orchards.

Key words: Basal callus, Rooting, Lulo, Micropropagation, Wild solanaceae.

\section{Introducción}

El uso de especies silvestres con el fin de mejorar la producción de cultivos de interés comercial, como el de lulo, es de gran interés para los fruticultores y se refleja en el aumento progresivo de la demanda de nuevos materiales vegetativos y cultivos alternativos para suplir la demanda de frutas en los mercados nacionales y para exportación [1-3]. De acuerdo con Lane [4] y Barrios-Paternina y Mercado-Gómez [5], los parientes silvestres de especies cultivadas comercialmente son fuente de genes de resistencia contra enfermedades, plagas y factores de estrés, como la sequía y las temperaturas extremas; una de tales especies es Solanum dolichosepalum (frutillo), arbusto nativo, escaso y propio de sitios abiertos, con adecuado desarrollo en suelos altamente erosionados secos y con deficiencias nutricionales [6].

El frutillo es importante en la cultura popular, sus hojas y frutos son utilizados como cicatrizante, para eliminar piojos y en el tratamiento de enfermedades renales [7]. Se ha comprobado que los extractos etanólicos de esta especie tienen efectos antibacterianos y antimicóticos contra Candida albicans [8], hongo productor de infecciones vaginales, intestinales y dermatológicas [9]. Además, sus extractos hidroalcohólicos poseen efectos inmunoestimulantes en ratas [10] y sus extractos acuosos muestran actividad antifúngica contra Trichophyton rubrum [11]. Por estas características y algunos ensayos realizados en nuestro Laboratorio (resultados no mostrados) se considera la posibilidad de que $S$. dolichosepalum presente algún grado de tolerancia a Fusarium oxysporum, hongo del suelo que produce marchitez vascular en plantas de lulo [12].

El injerto, además de ser una de las técnicas utilizadas para perpetuar clones de difícil multiplicación, acelerar la madurez de las plantas obtenidas por hibridación y para obtener formas especiales de crecimiento vegetativo, es de interés para el aprovechamiento de portainjertos resistentes tanto a patógenos como a diferentes condiciones de estrés [13]. En varias especies frutícolas se ha utilizado exitosamente el injerto para mejorar la producción; por ejemplo, portainjertos de S. torvum aumentan la producción de lulo a $5 \mathrm{t} \mathrm{ha}^{-1}$ [14], mientras que portainjertos de $S$. hirtum y $S$. arborium mejoran su diámetro, peso y acidez [15]. Además, la eficacia del uso de portainjertos resistentes a ciertos patógenos ha sido demostrada en varias especies como Lycopersicon hirsutum [16] y $S$. hirtum [17], especies silvestres que resultaron resistentes a $F$. oxysporum. Las ventajas que ofrece el uso de la técnica del injerto pueden ser complementadas con procesos de micropropagación que permitan la multiplicación clonal masiva de portainjertos cuidadosamente seleccionados, tanto por su compatibilidad (púa-portainjerto) como por su tolerancia a diferentes tipos de estrés [18, 19]. Por tanto, este trabajo se enfoca al establecimiento de un protocolo de micropropagación para $S$. dolichosepalum que permita obtener masivamente portainjertos clonales de alta calidad utilizables para multiplicar, a gran escala, materiales vegetativos de lulo de castilla.

\section{Metodología}

Esta investigación se realizó en el Laboratorio de Cultivo de Tejidos Vegetales BIOPLASMAUPTC de la Universidad Pedagógica y Tecnológica de Colombia, Tunja.

\subsection{Material vegetal}

Los arbustos silvestres de $S$. dolichosepalum utilizados están localizados en el municipio de TinjacáBoyacá $\left(05^{\circ} 34^{\prime} 51^{\prime \prime} \mathrm{N} 073^{\circ} 38^{\prime} 46^{\prime} \mathrm{O}^{\prime}, 2175 \mathrm{~m}\right.$ de altura y $17^{\circ} \mathrm{C}$ ); de éstos se colectaron frutos maduros, las semillas se extrajeron manualmente y posteriormente se sumergieron en una solución de Vitavax $囚$, $1,0 \mathrm{~g} \mathrm{~L}^{-1}$ durante 120 minutos, y se almacenaron en frascos de vidrio a temperatura ambiente hasta su uso. 
Tabla 1. Tratamientos aplicados para germinación de semillas de S. dolichosepalum.

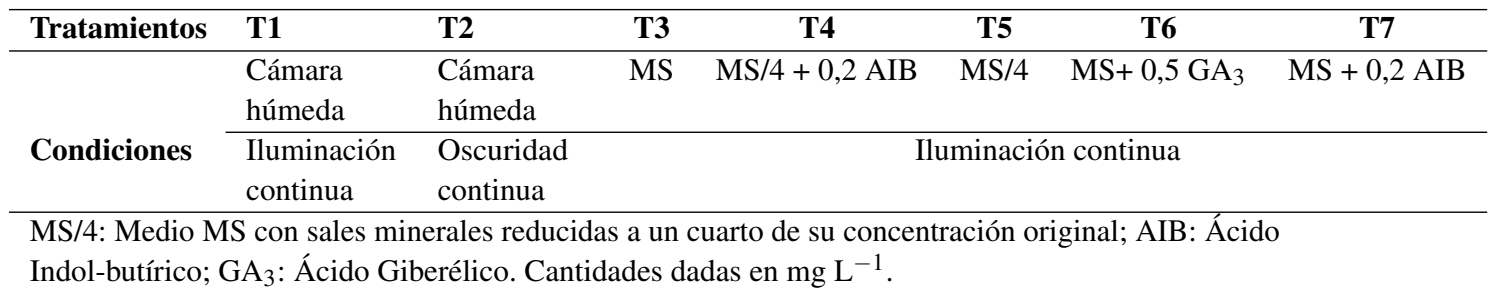

\subsection{Establecimiento de cultivos in vitro}

La asepsia superficial de las semillas se realizó siguiendo las recomendaciones de Bolívar y Tovar [20] para semillas de lulo. En cámara de flujo laminar, las semillas se enjuagaron con agua destilada estéril más Tween $20(0,1 \%$, v/v) durante 5 minutos y consecutivamente se sumergieron en etanol (70\%) durante 30 segundos y en $\mathrm{NaOCl}(5,25 \%$, $\mathrm{p} / \mathrm{v})$ al $10 \%(\mathrm{v} / \mathrm{v})$ durante 15 minutos con agitación continua. Finalmente, se enjuagaron cinco veces (1 minuto cada una) con agua destilada estéril.

Posteriormente, las semillas se cultivaron en medio MS, Murashige y Skoog [21], con o sin reguladores de crecimiento, en MS con sales diluidas a un cuarto (MS/4) o sobre papel filtro humedecido con agua destilada estéril (cámara húmeda) y se incubaron en condiciones de luz y oscuridad (tabla 1). Se realizaron observaciones consecutivas durante 30 días y en cada tratamiento se cuantificó el porcentaje de semillas germinadas y la contaminación por hongos y bacterias.

\subsection{Multiplicación de microtallos a través de segmentos nodales}

Después de 30 días de cultivo, y previa eliminación de la raíz, las plántulas obtenidas en la etapa anterior se transfirieron a MS suplementado con 0,2 $\mathrm{mg} \mathrm{L}^{-1}$ de AIB [20]. Con el fin de evitar la formación de callo basal en los microtallos desarrollados, así como de estimular la formación de yemas axilares y el enraizamiento, se realizaron diferentes ensayos (tabla 2) para evaluar el efecto de la posición del segmento nodal (explante) en el microtallo y de diferentes medios de cultivo, así como la concentración de: AIB y BA (solos o combinados), sales minerales MS en presencia de AIB, carbón activado y sales minerales MS y sacarosa en presencia o ausencia de carbón activado. En cada ensayo se cuantificó la longitud total promedio de microtallos, el promedio de yemas axilares neoformadas, el porcentaje de microtallos con callo basal y enraizados.

\subsection{Aclimatización}

Las plántulas obtenidas en la etapa anterior en los medios $\mathrm{H}$ y $\mathrm{H}$ con $2 \%$ sacarosa se extrajeron de los recipientes de cultivo, se les eliminó el agar adherido a las raíces con agua corriente y se transfirieron a vasos plásticos de $100 \mathrm{~mL}$ con diferentes sustratos: tierra, tierra:capote $(3: 1)$, tierra:turba $(3: 1)$, tierra:arena (3:1) y tierra:capote (mantillo de bosque):arena (3:2:1) y se mantuvieron en condiciones de invernadero con riego por nebulización cada 2 horas 6 segundos durante una semana y, posteriormente, con riego diario por aspersión manual durante 60 días. En esta etapa se cuantificó el porcentaje de plántulas viables.

\subsection{Condiciones generales de cultivo y análisis de datos}

La unidad experimental en la etapa de germinación fue un frasco con 10 semillas y cinco repeticiones para un total de 50 semillas por tratamiento; para la etapa de multiplicación la unidad experimental fue un frasco con cinco explantes (explante $=$ microtallo con uno o dos segmentos nodales) y seis repeticiones. Todos los explantes se cultivaron en recipientes de vidrio de $100 \mathrm{~mL}$, con alícuotas de $20 \mathrm{~mL}$ de medio de cultivo con $\mathrm{pH}$ de 5,6 ajustado con $\mathrm{HCl}$ y/o $\mathrm{NaOH} 0,1 \mathrm{~N}$ y autoclavados a $15 \mathrm{psi}$ y $121^{\circ} \mathrm{C}$ durante 20 minutos. Los cultivos se incubaron a $24 \pm 1^{\circ} \mathrm{C}$ con iluminación continua de $70-80 \mu \mathrm{mol}$ $\mathrm{m}^{-2} \mathrm{~s}^{-1}$, suministrada por lámparas fluorescentes de $75 \mathrm{~W}$.

Los datos se procesaron en el programa IBM SPSS Statisctics versión 22; para hallar diferencias significativas entre los tratamientos de germinación se realizó la prueba $\mathrm{H}$ de Kruskal-Wallis para muestras independientes y para los datos de multiplicación la prueba HSD Tukey con un nivel de confianza del 95\%; los datos de aclimatización se registraron y analizaron como porcentajes. 
Tabla 2. Condiciones físicas y medios de cultivo ensayados para multiplicación de yemas axilares de S. dolichosepalum. MS, Murashige y Skoog [21]; B5, Gamborg y col. [22]; Wh, Singh y Krikorian [23]; WPM, Lloyd y McCown [24]; A, Hussey y Stacey [25]; AT, Atkinson y Gardner [26]; H, Hendrix y col. [27]; Tto.=Tratamiento; Ctrol.= control; CA= Carbón activado; $\mathrm{AIB}=$ Ácido Indolbutírico, $\mathrm{BA}=$ Benciladenina, $\mathrm{ANA}=$ Ácido Naftalenacético. Cantidades dadas en $\mathrm{mg} \mathrm{L}^{-1}$.

\begin{tabular}{|c|c|c|c|c|c|c|c|c|c|c|c|c|c|c|c|}
\hline \multirow[t]{3}{*}{ ENSAYO } & \multirow[t]{3}{*}{ Tto. } & \multicolumn{14}{|c|}{ Condiciones } \\
\hline & & \multicolumn{9}{|c|}{ Medio } & \multirow[t]{2}{*}{$\mathbf{C A}$} & \multicolumn{3}{|c|}{ Reguladores } & \multirow[t]{2}{*}{ Otras } \\
\hline & & MS & MS/2 & MS/4 & B5 & Wh & WPM & $\mathbf{A}$ & AT & $\mathbf{H}$ & & AIB & BA & ANA & \\
\hline Ctrol. & & $\mathrm{X}$ & & & & & & & & & & & & & \\
\hline \multirow[t]{5}{*}{1} & 1 & $\mathrm{X}$ & & & & & & & & & & & & & Segmento \\
\hline & & & & & & & & & & & & & & & Apical \\
\hline & 2 & $\mathrm{X}$ & & & & & & & & & & & & & $\begin{array}{l}\text { Entrenudo } \\
\text { Superior }\end{array}$ \\
\hline & 3 & $\mathrm{X}$ & & & & & & & & & & & & & $\begin{array}{l}\text { Entrenudo } \\
\text { Medio }\end{array}$ \\
\hline & 4 & $\mathrm{X}$ & & & & & & & & & & & & & $\begin{array}{l}\text { Entrenudo } \\
\text { basal }\end{array}$ \\
\hline \multirow[t]{10}{*}{2} & 1 & $\mathrm{X}$ & & & & & & & & & & 0,2 & - & & Sacarosa 3\% \\
\hline & 2 & $\mathrm{X}$ & & & & & & & & & & 0,1 & - & & \\
\hline & 3 & $\mathrm{X}$ & & & & & & & & & & 0,05 & - & & \\
\hline & 4 & $\mathrm{X}$ & & & & & & & & & & 0,2 & 0,1 & & \\
\hline & 5 & $\mathrm{X}$ & & & & & & & & & & 0,1 & 0,1 & & \\
\hline & 6 & $\mathrm{X}$ & & & & & & & & & & 0,05 & 0,1 & & \\
\hline & 7 & $\mathrm{X}$ & & & & & & & & & & - & 0,05 & & \\
\hline & 8 & $\mathrm{X}$ & & & & & & & & & & - & 0,01 & & \\
\hline & 9 & $\mathrm{X}$ & & & & & & & & & & 0,01 & 0,05 & & \\
\hline & 10 & $\mathrm{X}$ & & & & & & & & & & 0,01 & 0,01 & & \\
\hline \multirow[t]{8}{*}{3} & 1 & & & $\mathrm{X}$ & & & & & & & & 0,2 & & & \\
\hline & 2 & & & $\mathrm{X}$ & & & & & & & & 0,1 & & & \\
\hline & 3 & & & $\mathrm{X}$ & & & & & & & & 0,05 & & & \\
\hline & 4 & & & X & & & & & & & & 0,025 & & & \\
\hline & 5 & & $X$ & & & & & & & & & 0,2 & & & Sacarosa $3 \%$ \\
\hline & 6 & & $X$ & & & & & & & & & 0,1 & & & \\
\hline & 7 & & $X$ & & & & & & & & & 0,05 & & & \\
\hline & 8 & & $\mathrm{X}$ & & & & & & & & & 0,025 & & & \\
\hline \multirow[t]{4}{*}{4} & 1 & $\mathrm{X}$ & & & & & & & & & 1000 & & & & Sacarosa $3 \%$ \\
\hline & 2 & & & & & & & & & & 1500 & & & & \\
\hline & 3 & & & & & & & & & & 2000 & & & & \\
\hline & 4 & & & & & & & & & & 3000 & & & & \\
\hline \multirow[t]{7}{*}{5} & 1 & $\mathrm{X}$ & & & & & & & & & 3000 & & & & Sacarosa $2 \%$ \\
\hline & 2 & $\mathrm{X}$ & & & & & & & & & 0 & & & & Sacarosa $2 \%$ \\
\hline & 3 & $\mathrm{X}$ & & & & & & & & & 3000 & & & & Sacarosa $3 \%$ \\
\hline & 4 & & $\mathrm{X}$ & & & & & & & & 3000 & & & & Sacarosa $2 \%$ \\
\hline & 5 & & $X$ & & & & & & & & 0 & & & & Sacarosa $2 \%$ \\
\hline & 6 & & $\mathrm{X}$ & & & & & & & & 3000 & & & & Sacarosa $3 \%$ \\
\hline & 7 & & $\mathrm{X}$ & & & & & & & & 0 & & & & Sacarosa 3\% \\
\hline \multirow[t]{7}{*}{6} & 1 & & & & $\mathrm{X}$ & & & & & & & & & & Sacarosa $3 \%$ \\
\hline & 2 & & & & & $\mathrm{X}$ & & & & & & & & & Sacarosa $3 \%$ \\
\hline & 3 & & & & & & $\mathrm{X}$ & & & & & & & & Sacarosa $3 \%$ \\
\hline & 4 & & & & & & & $\mathrm{X}$ & & & & & & & Sacarosa $3 \%$ \\
\hline & 5 & & & & & & & & $\mathrm{X}$ & & & & 1 & 0,1 & Sacarosa $3 \%$ \\
\hline & 6 & & & & & & & & & $\mathrm{X}$ & & & 0,02 & 0,02 & Sacarosa $3 \%$ \\
\hline & 7 & & & & & & & & & $X$ & & & 0,02 & 0,02 & Sacarosa $2 \%$ \\
\hline
\end{tabular}

\section{Resultados y discusión}

\subsection{Establecimiento de cultivos}

Para la asepsia superficial de semillas de S. dolichosepalum la aplicación de $\mathrm{NaOCl}$ al $10 \%$ (v/v) durante 15 minutos resultó efectiva permitiendo obtener $100 \%$ de cultivos de semillas asépticas, resultados que concuerdan con los obtenidos en explantes de otras solanáceas como Solanum quitoense, Physalis ixocarpa, P. minima y P. peruviana $[18,28,29]$. Téngase en cuenta que el $\mathrm{NaOCl}$ aparece en la literatura como uno de los agentes desinfectantes más utilizados en cultivo de tejidos [30, 31]. Todos los tratamientos ensayados para la obtención de plántulas in vitro (figura 1) mostraron diferencias significativas en el porcentaje de germinación, cuantificándose el valor más alto (100\%) en MS/4 (T5); en los demás tratamientos los valores de germinación no superaron el $32 \%$, o no se observó germinación como en el tratamiento en MS (T3) y MS $+0,2 \mathrm{mg} \mathrm{L}^{-1}$ de AIB (T7). 


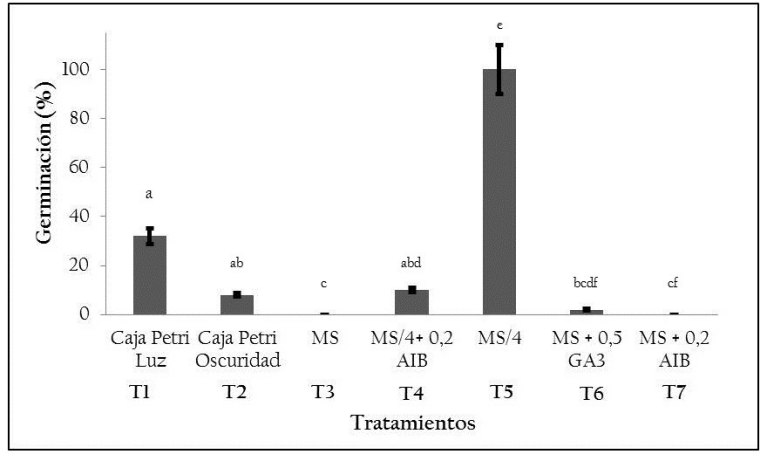

Figura 1. Efecto de la luz y diferentes medios de cultivo sobre la germinación de semillas de S. dolichosepalum. Datos registrados después de 20 días de cultivo. Barras con letras distintas indican diferencia significativa según la prueba de Kruskal-Wallis $\left(\mathrm{X}^{2}(1)=50,28, \mathrm{P} \leq 0,05\right)$. Las barras sobre las columnas indican la desviación estándar.

La variación en los porcentajes de germinación registrada en los tratamientos ensayados indica que tanto la elevada concentración de sales del medio (MS), como la presencia de AIB, GA 3 y AIB inhiben totalmente la germinación (T3) o la inhiben parcialmente (T4, T6, T7); además, la baja germinación en cajas de Petri pone en evidencia el efecto positivo de la presencia de bajas concentraciones de sales en el medio de cultivo. En los tratamientos T1 y T2 también se pone en evidencia el efecto promotor de la luz sobre la germinación de semillas. Así mismo, el $100 \%$ de germinación alcanzado en el medio pobre en sales (MS/4) indica que las semillas cultivadas se encontraban en un estado óptimo de madurez morfofisiológica, condición que facilitó una rápida emergencia de radícula, 7-9 días, y un desarrollo de plántulas de apariencia normal. Resultados semejantes fueron reportados en semillas de otras solanáceas silvestres [32], de las cuales semillas de $S$. hirtum cultivadas en medio Hendrix $(\mathrm{H})$ y de $S$. mammosum cultivadas en MS diluido a la mitad de su concentración original alcanzaron valores de $94,4 \%$ y $90,6 \%$, respectivamente. Además, la escasa germinación en condiciones de oscuridad podría indicar que las semillas de $S$. dolichosepalum se comportan como fotoblásticas positivas; este comportamiento también se ha reportado para semillas de S. sessiliflorum [33], S. nudum [34], S. quitoense y $S$. betaceum [35], entre otras.

\subsection{Multiplicación de microtallos a través de segmentos nodales}

Ensayo 1. Efecto de la posición del segmento nodal en el microtallo. De manera semejante a las observaciones realizadas por otros autores [36, 37], en este ensayo fue evidente la variación de las respuestas producidas por explantes tomados de diferentes posiciones de los tallos desarrollados in vitro. Las respuestas cuantificadas en los tratamientos en los que se cultivaron segmentos apicales, superiores, medios y basales presentaron diferencias significativas (HSD Tukey, $\mathrm{P} \leq 0,05$ ) en las variables longitud total, yemas axilares neoformadas y microtallos con callo basal, mientras que los porcentajes de enraizamiento fueron elevados y menos variables, 90-100\%, (tabla 3). Los microtallos con mayor longitud total $(5,1 \mathrm{~cm})$ se desarrollaron de segmentos nodales superiores, formaron en promedio 4,3 yemas axilares y el $100 \%$ formó raíces, sin embargo, la formación de callo alcanzó el $100 \%$, respuesta que puede deberse, en parte, a la cercanía de dichos segmentos al meristemo apical, sitio principal de síntesis de AIA. Se ha sugerido que la eficiencia del explante utilizado en la formación de yemas y desarrollo de microtallos disminuye con el incremento en la distancia desde el ápice del tallo principal [38]. Aunque en segmentos basales, en comparación con los segmentos apicales, la longitud total de microtallos disminuyó a 3,7 cm y el número promedio de yemas axilares a 3,5 , este tipo de explante fue seleccionado como el más adecuado para la realización de los ensayos siguientes debido a que la formación de callo disminuyó a $50 \%$. Resultados semejantes a los obtenidos en este trabajo se han reportado para Annona muricata [37] y Psidium guajava [38] en las que se observó que los segmentos nodales intermedios desarrollaron mayor número de yemas axilares que los segmentos nodales superiores y basales; así mismo, en Quercus robur los explantes tomados de regiones basales y apicales produjeron la menor cantidad brotes [39]. Con relación a la formación de callo, se ha indicado que la capacidad de formación de callo en segmentos caulinares de una misma planta varía según la posición del explante a lo largo del tallo, observando que los explantes más cercanos a la inserción de los cotiledones reaccionan mejor que los situados más arriba [40]. Estos resultados contrastan con los obtenidos en $S$. dolichosepalum, en el que los mayores porcentajes de segmentos nodales que formaron callo fueron los más cercanos al ápice. 
Tabla 3. Efecto de la posición del segmento nodal en el microtallo sobre la longitud total, formación de yemas axilares, desarrollo de callo basal y enraizamiento de microtallos de $S$. dolichosepalum. Valores en una misma columna seguidos de letras iguales no presentan diferencias significativas, según la prueba HSD Tukey $(\mathrm{P} \leq 0,05)$.

\begin{tabular}{llllll}
\hline Tratamiento & $\begin{array}{l}\text { Segmento } \\
\text { Nodal }\end{array}$ & $\begin{array}{l}\text { Longitud total } \\
(\mathbf{c m})\end{array}$ & $\begin{array}{l}\text { Yemas axilares } \\
\text { neoformadas } \\
(\hat{x})\end{array}$ & $\begin{array}{l}\text { Microtallos } \\
\text { con callo basal } \\
(\boldsymbol{\%})\end{array}$ & $\begin{array}{l}\text { Microtallos en- } \\
\text { raizados }(\%)\end{array}$ \\
\hline T1 & Apical & $4,3(\mathrm{a})$ & $3,1(\mathrm{a})$ & $90(\mathrm{ab})$ & $100(\mathrm{a})$ \\
T2 & Superior & $5,1(\mathrm{~b})$ & $4,3(\mathrm{c})$ & $100(\mathrm{a})$ & $100(\mathrm{a})$ \\
T3 & Medio & $3,8(\mathrm{a})$ & $3,9(\mathrm{bc})$ & $100(\mathrm{a})$ & $90(\mathrm{a})$ \\
T4 & Basal & $3,7(\mathrm{a})$ & $3,5(\mathrm{ab})$ & $50(\mathrm{ab})$ & $90(\mathrm{a})$ \\
\hline
\end{tabular}

Tabla 4. Efecto de la concentración de AIB y BA sobre la longitud total, formación de yemas axilares, desarrollo de callo basal y enraizamiento de microtallos de $S$. dolichosepalum. Valores en una misma columna seguidos de letras iguales no difieren en forma significativa, según la prueba HSD Tukey $(\mathrm{P} \leq 0,05)$.

\begin{tabular}{|c|c|c|c|c|c|c|}
\hline \multirow[t]{2}{*}{ Tratamiento } & \multicolumn{2}{|c|}{ Hormona } & \multirow{2}{*}{$\begin{array}{l}\text { Longitud total } \\
(\mathrm{cm})\end{array}$} & \multirow{2}{*}{$\begin{array}{l}\text { Yemas } \\
\text { axilares } \\
(\hat{x})\end{array}$} & \multirow{2}{*}{$\begin{array}{l}\text { Microtallos } \\
\text { con callo basal } \\
(\%)\end{array}$} & \multirow{2}{*}{$\begin{array}{l}\text { Microtallos en- } \\
\text { raizados (\%) }\end{array}$} \\
\hline & $\operatorname{AIB}\left(\mathrm{mg} \mathrm{L}^{-1}\right)$ & $\mathbf{B A}\left(\mathrm{mg} \mathrm{L} \mathrm{L}^{-1}\right)$ & & & & \\
\hline Control & - & - & $3,2(a b)$ & $4(\mathrm{bc})$ & 100 (a) & $13,3(d)$ \\
\hline $\mathrm{T} 1$ & 0,2 & - & $6,3(\mathrm{e})$ & $3(a b)$ & 93,3 (a) & $66,6(a b c)$ \\
\hline $\mathrm{T} 2$ & 0,1 & - & $5(d)$ & $5(\mathrm{~cd})$ & $100(a)$ & $80(a b)$ \\
\hline $\mathrm{T} 3$ & 0,05 & - & 4,8 (cd) & $4(a b c)$ & 53,3 (b) & 40 (abcd) \\
\hline $\mathrm{T} 4$ & 0,2 & 0,1 & 3,9 (bcd) & $6(d)$ & $66,6(a b)$ & 86,6 (a) \\
\hline T5 & 0,1 & 0,1 & 4,1 (bcd) & 3 (a) & $73,3(a b)$ & $80(a b)$ \\
\hline T6 & 0,05 & 0,1 & 3,8 (abcd) & $5(\mathrm{~cd})$ & $68(a b)$ & 33,3 (bcd) \\
\hline $\mathrm{T} 7$ & - & 0,05 & 3,8 (bcd) & $6(d)$ & 100 (a) & $20(\mathrm{~cd})$ \\
\hline T8 & - & 0,01 & 2,6 (a) & $4(a b c)$ & 100 (a) & $20(\mathrm{~cd})$ \\
\hline T9 & 0,01 & 0,05 & 4 (bcd) & 3 (a) & 100 (a) & 40 (abcd) \\
\hline $\mathrm{T} 10$ & 0,01 & 0,01 & $3,6(a b c)$ & $3(a)$ & $100(a)$ & $26,6(\mathrm{~cd})$ \\
\hline
\end{tabular}

Ensayo 2. Efecto del AIB y BA. Los datos registrados para las variables evaluadas presentaron diferencias significativas entre los tratamientos (HSD Tukey $\mathrm{P} \leq 0,05$ ) (tabla 4). Con respecto a la longitud total de microtallos los valores más elevados, 4,8 y $6,3 \mathrm{~cm}$, se cuantificaron en presencia de AIB (T3 y $\mathrm{T} 1$ ), mientras que en los medios con BA, (T7 y T8) la longitud fue de 2,6 y $3,8 \mathrm{~cm}$ y, en presencia de auxina más citoquinina, alcanzó valores intermedios a los anteriores, 3,6-4,1 cm. Resultados similares fueron reportados por Rache y Pacheco [29] en la propagación in vitro de Physalis peruviana, e indicaron que en presencia de $\operatorname{AIB}(0,1 \mathrm{mg} / \mathrm{L})$ se obtuvo la mayor longitud de microtallos $(8,6 \mathrm{~cm})$ y que en presencia de BA la elongación fue deficiente (máximo $2,7 \mathrm{~cm}$ ); así mismo, en S. glaucescens Medina [41] obtuvo la mayor longitud, $11,10 \mathrm{~cm}$, de brotes en presencia de 1,0 $\mathrm{mg} / \mathrm{L}$ de AIB. En relación con la presencia de auxinas en los medios utilizados, los datos obtenidos ponen en evidencia el efecto estimulante de las auxinas sobre la elongación de los microtallos de S. dolichosepalum, el cual contrasta con el reportado para otras solanáceas cultivadas in vitro (Capsicum annuum [42] y Physalis ixocarpa [28]), las cuales elongan adecuadamente en medios suplementados con citoquininas.
Con relación a formación de yemas axilares por microtallo, se observó que los promedios fueron afectados de forma variable principalmente por las concentraciones de AIB y BA utilizadas en los diferentes tratamientos (tabla 4). Aunque no es posible determinar cuantitativamente una relación especifica entre la concentración de citoquinas en el medio y el número de yemas axilares formadas, se observó que en el tratamiento en presencia solo de BA (T7) y este acompañado con una concentración mayor de AIB (T4), la formación de yemas fue mayor; mientras en presencia de concentraciones bajas de BA y AIB (solas o combinadas) los microtallos formaron $3 \mathrm{a}$ 4 yemas axilares (T3,T5,T8,T9 y T10); resultados similares, 4,3 yemas por explante, se obtuvieron en uchuva con $0,1 \mathrm{mg} \mathrm{L}^{-1}$ de AIB [29].

El desarrollo de callo se presentó en altos porcentajes de microtallos (66,6-100\%) en todos los tratamientos realizados incluyendo el control, cuantificándose el más bajo $(53,3 \%)$ en presencia de 0,05 $\mathrm{mg} / \mathrm{L}$ de AIB. El callo formado presentó consistencia friable y su crecimiento inició en la base (figura 2a), avanzó en dirección ascendente (figura $2 b$ ) hasta invadir totalmente al microtallo y presentar apariencia necrótica (figura 2c). En contraste con las observacio- 
nes anteriores, en numerosas solanáceas las auxinas y citoquininas (solas o combinadas) en los medios de cultivo promueven procesos de división celular y activación enzimática [43] facilitando, no solo la formación de callo sino el desarrollo de procesos organogénicos [40, 44, 45].

Los porcentajes de enraizamiento de microtallos también resultaron estadísticamente diferentes; el AIB, solo, en el medio de cultivo indujo enraizamiento en 40-80\% de los microtallos (T1, T2 y T3), mientras que el BA, solo, inhibió en gran medida el enraizamiento, cuantificándose valores de $20 \%$ (T7 y T8). Por otro lado, se observó que la adición al medio de cultivo de auxina+citoquinina estimuló el enraizamiento en más del $80 \%$ de los microtallos (T4 y T5); respuesta que puede ser explicada por el efecto sinérgico de estas dos hormonas, el cual favorece el desarrollo de raíces cuando existe un balance a favor de las auxinas (T4). Al respecto, Rache y Pacheco [29] reportaron la misma concentración utilizada en este estudio en T2 $\left(0,1 \mathrm{mg} \mathrm{L}^{-1}\right.$ de AIB) en la cual el $100 \%$ de los microtallos de $P$. peruviana desarrollaron raíces.

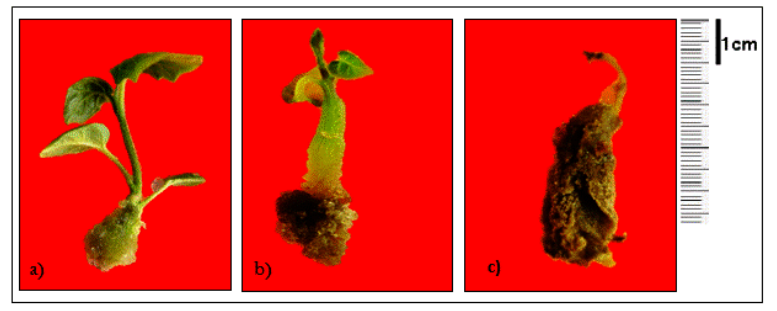

Figura 2. Desarrollo de callo en microtallos de S. dolichosepalum. a) Callo formado en la superficie del explante en contacto con el medio de cultivo; b) Crecimiento del callo en dirección apical y necrosis basal; c) Explante invadido por callo necrosado.

Ensayo 3. Efecto de la concentración de sales minerales MS en presencia de AIB. La reducción de las sales minerales del MS a $1 \frac{1}{2}$ y $1 / 4$ de su concentración original en presencia de AIB entre 0,025 y 0,2 $\mathrm{mg} \mathrm{L}^{-1}$ (tabla 2), afectó de manera significativa los resultados obtenidos en las variables evaluadas, excepto la formación de callo basal, la cual alcanzó un valor de $100 \%$ en todos los tratamientos (tabla 5). La longitud total de microtallos en todos los tratamientos fue mayor a $3,8 \mathrm{~cm}$ y los promedios más altos, 6,4 y $6,2 \mathrm{~cm}$, se obtuvieron en MS/4 + 0,1 $\mathrm{mg} \mathrm{L}^{-1} \mathrm{de}$ AIB y MS $/ 2+0,05 \mathrm{mg} \mathrm{L}^{-1}$ de AIB (T2 y T7, respectivamente); sin embargo, en ambos tratamientos los microtallos solo desarrollaron en promedio tres ye- mas axilares, cantidad inferior a la obtenida en MS/4 + 0,05 $\mathrm{mg} \mathrm{L}^{-1}$ de AIB (T3) y MS/2 + 0,2 $\mathrm{mg} \mathrm{L}^{-1}$ de AIB (T5). El porcentaje de microtallos enraizados varió entre 13,3 y $90 \%$; este último porcentaje se registró en T3, tratamiento en el que los microtallos alcanzaron una longitud de $5,2 \mathrm{~cm}$ y desarrollaron en promedio cinco yemas axilares.

Con frecuencia se ha señalado un efecto negativo de la reducción de las sales minerales del medio sobre el crecimiento in vitro de explantes, puesto que la función esencial de los micro y macronutrientes es mantener su crecimiento y desarrollo [46]; contrastando con lo anterior, en algunos de los tratamientos de este ensayo (T3 y T5) el comportamiento de las variables evaluadas muestra un efecto positivo de dicha reducción sobre la multiplicación de los microtallos de $S$. dolichosepalum, obteniéndose microtallos con longitudes de 5,2 y $6,0 \mathrm{~cm}$, las cuales facilitaron la individualización de las yemas axilares neoformadas; conviene subrayar que los valores de longitud de microtallos resultaron semejantes al reducir las sales minerales del MS, tanto a $1 / 2$ como $1 / 4$, superando la obtenida en el tratamiento control (MS). La respuesta de enraizamiento fue similar en los tratamientos agrupados por la reducción de sales minerales $(1 / 4=\mathrm{T} 1-\mathrm{T} 4$ y $1 / 2=\mathrm{T} 5$-T 8$)$; en cada grupo un solo tratamiento difirió estadísticamente de los demás, que es aquel en el que se obtiene el mayor porcentaje de enraizamiento, $\mathrm{T} 3 \mathrm{y} \mathrm{T} 8$, con $90 \%$ y $80 \%$, respectivamente; con respecto al enraizamiento, O'Connor-Sánchez y col. [44] reportaron que brotes regenerados de hojas de $S$. donianum enraizaron en mayor porcentaje en un medio con la mitad de la concentración original de sales MS y sin reguladores de crecimiento.

Ensayo 4. Efecto del carbón activado. La adición de carbón activado (CA) al medio de cultivo mostró un efecto significativo sobre la formación de callo basal y aunque no se observó una relación proporcional entre su concentración y el porcentaje de microtallos con callo, la presencia de CA en el medio de cultivo sí disminuyó dicho porcentaje (tabla 6). Teniendo como referencia los datos registrados en el tratamiento control (MS), concentraciones de 2,0; 1,5; 1,0 y 3,0 g/L de CA produjeron una disminución de $20,30,40$ y $100 \%$, respectivamente, de microtallos con callo. Aunque en presencia de $3,0 \mathrm{~g} \mathrm{~L}^{-1}$ de CA el $100 \%$ de los microtallos no formaron callo, 
Tabla 5. Efecto de la concentración de sales minerales MS en presencia de AIB sobre la longitud total, formación de yemas axilares, desarrollo de callo basal y enraizamiento de microtallos de $S$. dolichosepalum. Valores en una misma columna seguidos de letras iguales no difieren en forma significativa, según la prueba HSD Tukey $(\mathrm{P} \leq 0,05)$.

\begin{tabular}{|c|c|c|c|c|c|c|}
\hline \multirow[t]{2}{*}{ Tratamiento } & \multicolumn{2}{|c|}{ Medio } & \multirow{2}{*}{$\begin{array}{l}\text { Longitud } \\
\text { total }(\mathrm{cm})\end{array}$} & \multirow{2}{*}{$\begin{array}{l}\text { Yemas axilares } \\
\text { neoformadas } \\
(\hat{x})\end{array}$} & \multirow{2}{*}{$\begin{array}{l}\text { Microtallos } \\
\text { con callo ba- } \\
\text { sal }(\%) \\
\end{array}$} & \multirow{2}{*}{$\begin{array}{l}\text { Microtallos } \\
\text { enraizados } \\
(\%) \\
\end{array}$} \\
\hline & $\begin{array}{l}\text { Concentración } \\
\text { Sales MS }\end{array}$ & AIB $\left(\mathrm{mg} \mathrm{L}^{-1}\right)$ & & & & \\
\hline Control & 1 & - & 3,2 (a) & $4(\mathrm{bc})$ & 100 & 13,3 (b) \\
\hline $\mathrm{T} 1$ & $1 / 4$ & 0,2 & $5,4(b c)$ & $4(a b c)$ & 100 & $60(a b)$ \\
\hline $\mathrm{T} 2$ & & 0,1 & $6,4(c)$ & $3(a b)$ & 100 & $70(a b)$ \\
\hline $\mathrm{T} 3$ & & 0,05 & $5,2(b c)$ & $5(\mathrm{c})$ & 100 & $90(a)$ \\
\hline $\mathrm{T} 4$ & & 0,025 & 3,8 (a) & $3(a b)$ & 100 & $40(a b)$ \\
\hline T5 & $1 / 2$ & 0,2 & $6(c)$ & $5(\mathrm{c})$ & 100 & $60(a b)$ \\
\hline T6 & & 0,1 & $4,1(a b)$ & $4(a b)$ & 100 & $50(a b)$ \\
\hline $\mathrm{T} 7$ & & 0,05 & $6,2(\mathrm{c})$ & $3(\mathrm{c})$ & 100 & $70(a b)$ \\
\hline T8 & & 0,025 & $5,7(\mathrm{c})$ & $4(\mathrm{ab})$ & 100 & $80(a)$ \\
\hline
\end{tabular}

se observó clorosis y defoliación (figura 3 a, b y c), respuestas semejantes a las obtenidas por Rosati y col. [47] en cultivos in vitro de brotes de Prunus silicina. Las variables longitud de microtallos, yemas axilares neoformadas y porcentaje de enraizamiento presentaron valores de 3 a $4,3 \mathrm{~cm}, 3$ a 5 yemas axilares y 80 a $100 \%$ de enraizamiento.

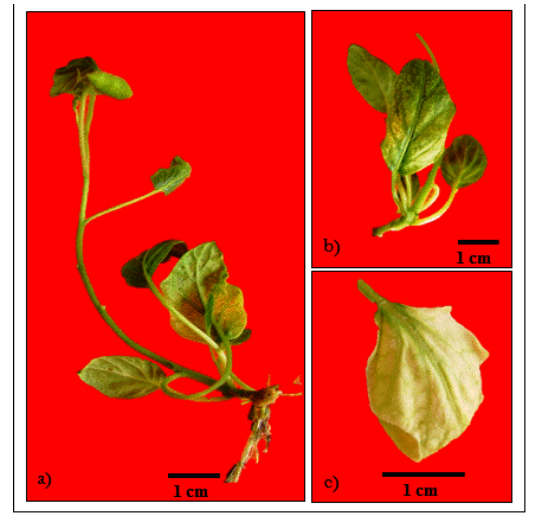

Figura 3. Clorosis foliar en explantes cultivados en MS suplementado con $3 \mathrm{~g} \mathrm{~L}^{-1}$ de CA. a) Microtallo con hojas basales cloróticas; b) Desarrollo del proceso clorótico; c) Hoja completamente clorótica.

La adición de CA al medio de cultivo es una práctica reconocida y su influencia sobre el crecimiento y desarrollo de explantes cultivados se puede atribuir a la adsorción de sustancias inhibitorias presentes en el medio de cultivo [48], la disminución de procesos de oxidación [49], la alteración del pH del medio a un nivel óptimo para la morfogénesis [50], y al mantenimiento de un ambiente oscurecido que simula las condiciones del suelo [51]; dicha influencia también se observó en este trabajo (tabla 6) y con efectos semejantes a los obtenidos por Borges y Sosa [52] en Dioscorea spp cuando adicionaron 0,5 a $2 \mathrm{~g} \mathrm{~L}^{-1}$ de CA al medio MS para estimular crecimiento de nudos, hojas y tallos.

Ensayo 5. Efecto de la concentración de sales minerales y sacarosa en presencia de carbón activado. De acuerdo con los resultados de la prueba HSD Tukey $(\mathrm{P} \leq 0,05)$ la combinación de sales minerales MS reducidas o no a $1 / 2$, con 20 ó $30 \mathrm{~g} \mathrm{~L}^{-1}$ de sacarosa y con $3 \mathrm{~g} \mathrm{~L}^{-1}$ ó sin carbón activado, mostró diferencias significativas para las variables longitud total del microtallo y número promedio de yemas axilares neoformadas, mientras que el porcentaje de microtallos con callo basal y enraizados mostró un comportamiento uniforme (tabla 7). Los microtallos con mayor longitud $(5,3 \mathrm{~cm})$ se desarrollaron en $\mathrm{MS} / 2$, con $30 \mathrm{~g} \mathrm{~L}^{-1}$ de sacarosa y sin carbón activado (T7); en este tratamiento, cada microtallo formó en promedio cuatro yemas axilares y el 50\% de los microtallos desarrolló callo basal y raíces. En MS, con $20 \mathrm{~g} \mathrm{~L}^{-1}$ de sacarosa y sin carbón activado (T2) los microtallos alcanzaron $4,7 \mathrm{~cm}$, formaron en promedio cinco yemas, tan solo el $30 \%$ mostró desarrollo de callo basal y el $90 \%$ desarrolló raíces. Estos resultados muestran un efecto proporcional de la concentración de la fuente de carbono sobre la formación de callo en la base del explante, ya que en aquellos tratamientos en los que se disminuyó la concentración de sacarosa a $20 \mathrm{~g} \mathrm{~L}^{-1}$ (manteniendo la concentración original de sales minerales de MS) se obtuvo el menor porcentaje de microtallos con callo basal (T1 y T2) y, tanto la longitud total de microtallos como el número de yemas axilares neoformadas, presentaron valores de 4,1-4,7 $\mathrm{cm}$ y 4-4,9, respectivamente. Sin embargo, la disminución de sacarosa indujo el desarrollo de microtallos notoriamente delgados con escaso desarrollo radical, 
Tabla 6. Efecto de la concentración de carbón activado sobre la longitud total, formación de yemas axilares, desarrollo de callo basal y enraizamiento de microtallos de $S$. dolichosepalum cultivados en MS. Valores en una misma columna seguidos de letras iguales no difieren en forma significativa, según la prueba HSD Tukey $(\mathrm{P} \leq 0,05)$.

\begin{tabular}{llllll}
\hline Tratamiento & $\begin{array}{l}\text { Carbón acti- } \\
\text { vado }\left(\mathrm{g} \mathrm{L}^{-1}\right)\end{array}$ & $\begin{array}{l}\text { Longitud } \\
\text { total }(\mathbf{c m})\end{array}$ & $\begin{array}{l}\text { Yemas axilares } \\
\text { neoformadas }(\hat{x})\end{array}$ & $\begin{array}{l}\text { Microtallos } \\
\text { con callo basal } \\
(\%)\end{array}$ & $\begin{array}{l}\text { Microtallos } \\
\text { enraizados } \\
(\%)\end{array}$ \\
\hline Control & 0 & $3,2(\mathrm{ab})$ & $4(\mathrm{~b})$ & $100(\mathrm{a})$ & $13,3(\mathrm{~b})$ \\
T1 & 1 & $3,5(\mathrm{abc})$ & $3,8(\mathrm{a})$ & $70(\mathrm{ab})$ & $100(\mathrm{a})$ \\
T2 & 1,5 & $4,2(\mathrm{bc})$ & $4,6(\mathrm{~b})$ & $60(\mathrm{~b})$ & $90(\mathrm{a})$ \\
T3 & 2 & $3(\mathrm{a})$ & $2,6(\mathrm{a})$ & $80(\mathrm{ab})$ & $70(\mathrm{a})$ \\
T4 & 3 & $4,6(\mathrm{c})$ & $3(\mathrm{a})$ & $0(\mathrm{c})$ & $80(\mathrm{a})$ \\
\hline
\end{tabular}

resultado que puede explicarse, en parte, por la función que cumple la sacarosa como fuente energética del metabolismo celular [53]. Téngase en cuenta que la sacarosa en concentraciones altas aumenta el crecimiento y vigor de hojas, tallos y raíces, mientras que en bajas concentraciones el desarrollo de los explantes es más lento y de menor vigor $[46,54]$. Aunque la disminución de la concentración de sacarosa redujo notoriamente la formación de callo, no se consideró adecuada para la multiplicación de microtallos por su efecto negativo sobre los procesos de crecimiento y desarrollo de explantes.

Ensayo 6. Efecto de diferentes medios de cultivo. La utilización de diferentes medios de cultivo permitió observar diferencias significativas entre los datos registrados para las variables analizadas (tabla 8); en el medio $\mathrm{H}$ los microtallos alcanzaron la mayor longitud, $5,1 \mathrm{~cm}$, formaron en promedio 4 yemas axilares, el $100 \%$ desarrollaron raíces y tan solo el 11,4\% formó callo basal. En el medio B5 también se obtuvo un bajo porcentaje $(20 \%)$ de explantes con callo, sin embargo, tanto la longitud total como el número de yemas axilares fueron los más bajos (2,2 cm y 1,4 yemas, respectivamente). En los medios restantes MS, Wh, WPM, A, AT, las respuestas alcanzaron valores intermedios en cada una de las variables evaluadas: la longitud total de microtallos entre 3 y $4,4 \mathrm{~cm}$, el número de yemas axilares neoformadas entre 2 y 4 , el enraizamiento entre 13,3 y $95 \%$ y, la formación de callo basal entre 85 y $100 \%$ de los microtallos cultivados. En el medio $\mathrm{H}$ con $2 \%$ de sacarosa se cuantificó el menor porcentaje de explantes con callo basal (3\%) y las demás variables con valores adecuados para realizar una micropropagación exitosa. En contraste con los resultados obtenidos en el presente estudio, Lentini y col.[55] observaron que explantes de $S$. quitoense cultivados en medio A presentaron un desarrollo radical más temprano y abundante que el alcanzado en los medios $\mathrm{H}$, AT y
MS reducido a la mitad de su concentración original.

Por otra parte, en el trabajo realizado por Andrade y col. [31] con otras solanáceas silvestres, se determinó que para $S$. mammosum el medio adecuado para la multiplicación a través de segmentos nodales fue el A, mientras que, igual que para $S$. $d o$ lichosepalum, para S. marginatum, S. umbellatum y S. hirtum fue el medio H. La característica particular del medio $\mathrm{H}$ es la ausencia de mioinositol como fuente de carbono que usualmente se asocia con la estimulación del crecimiento de callos y suspensiones celulares [56], lo cual explica en parte, los bajos porcentajes de microtallos que formaron callo basal; además, la presencia de cantidades semejantes de ANA y BA $\left(0,02 \mathrm{mg} \mathrm{L}^{-1}\right)$ en este medio mostraron ser concentraciones que permiten obtener valores de longitud total de microtallos, número de yemas axilares y porcentaje de enraizamiento adecuados para un proceso exitoso de micropropagación, ya que el efecto organogénico del ANA se ha observado, por ejemplo, en $S$. quitoense cultivado en medio MS con concentraciones por encima de $0,5 \mathrm{mg} \mathrm{L}^{-1}$, en este medio se induce la formación de callos-masas con crecimiento continuo [57].

\subsection{Aclimatización}

A pesar de ser una etapa crítica de los procesos de micropropagación, en todos los sustratos utilizados en este trabajo para la aclimatización se cuantificaron altos porcentajes de plántulas viables, siendo el más adecuado la mezcla de tierra, capote y arena, 3:2:1 (figura 4). López y col. [58] y Díaz y col. [59] utilizaron esta mezcla junto con cascarilla de arroz y obtuvieron más del $90 \%$ de plántulas viables de Physalis peruviana. De acuerdo con Rache y Pacheco [29] el uso de capote (mantillo de bosque) durante la etapa de aclimatización favorece la viabilidad de plántulas con crecimiento sostenido y 
Tabla 7. Efecto de la concentración de sales minerales, sacarosa y carbón activado sobre la longitud total, formación de yemas axilares, desarrollo de callo basal y enraizamiento de microtallos de $S$. dolichosepalum. Valores en una misma columna seguidos de letras iguales no difieren en forma significativa, según la prueba HSD Tukey $(\mathrm{P} \leq 0,05)$.

\begin{tabular}{llllllll}
\hline Tratamiento & $\begin{array}{l}\text { Concentración } \\
\text { Sales MS }\end{array}$ & $\begin{array}{l}\text { Sacarosa } \\
\left(\mathrm{g} \mathrm{L}^{-1}\right)\end{array}$ & $\begin{array}{l}\text { Carbón } \\
\text { activado } \\
\left(\mathrm{g} \mathrm{L}^{-1}\right)\end{array}$ & $\begin{array}{l}\text { Longitud } \\
\text { total }(\mathbf{c m})\end{array}$ & $\begin{array}{l}\text { Yemas axilares } \\
\text { Neoformadas } \\
(\hat{x})\end{array}$ & $\begin{array}{l}\text { Microtallos } \\
\text { con } \\
\text { ballo } \\
\text { basal }(\boldsymbol{\%})\end{array}$ & $\begin{array}{l}\text { Microtallos } \\
\text { enraizados } \\
(\%)\end{array}$ \\
\hline Control & 1 & 30 & - & $3,2(\mathrm{a})$ & $4(\mathrm{ab})$ & $100(\mathrm{a})$ & $13,3(\mathrm{c})$ \\
T1 & 1 & 20 & 3 & $4,1(\mathrm{abc})$ & $4(\mathrm{ab})$ & $40(\mathrm{ab})$ & $50(\mathrm{ab})$ \\
T2 & & 20 & - & $4,7(\mathrm{bc})$ & $4,9(\mathrm{~b})$ & $30(\mathrm{~b})$ & $90(\mathrm{a})$ \\
T3 & 30 & 3 & $4,0(\mathrm{ab})$ & $4,6(\mathrm{ab})$ & $60(\mathrm{ab})$ & $80(\mathrm{a})$ \\
T4 & $1 / 2$ & 20 & 3 & $4,0(\mathrm{ab})$ & $3,5(\mathrm{a})$ & $50(\mathrm{ab})$ & $40(\mathrm{ab})$ \\
T5 & & 20 & - & $3,1(\mathrm{a})$ & $4,5(\mathrm{ab})$ & $50(\mathrm{ab})$ & $60(\mathrm{ab})$ \\
T6 & 30 & 3 & $3,3(\mathrm{a})$ & $4,9(\mathrm{~b})$ & $60(\mathrm{ab})$ & $40(\mathrm{ab})$ \\
T7 & & 30 & - & $5,3(\mathrm{c})$ & $4,4(\mathrm{ab})$ & $50(\mathrm{ab})$ & $50(\mathrm{ab})$ \\
\hline
\end{tabular}

Tabla 8. Efecto de diferentes medios de cultivo sobre la longitud total, formación de yemas axilares, desarrollo de callo basal y enraizamiento de microtallos de $S$. dolichosepalum. Valores en una misma columna seguidos de letras iguales no difieren en forma significativa, según la prueba HSD Tukey $(\mathrm{P} \leq 0,05)$. MS, Murashige y Skoog [21]; B5, Gamborg y col. [22]; Wh, Singh y Krikorian [23]; WPM, Lloyd y McCown [24]; A, Hussey y Stacey [25]; AT, Atkinson y Gardner [26], H, Hendrix y col. [27].

\begin{tabular}{lllllll}
\hline Tratamiento & Medio & $\begin{array}{l}\text { Longitud } \\
\text { (cm) }\end{array}$ & total & $\begin{array}{l}\text { Yemas axilares } \\
\text { Neoformadas }(\hat{x})\end{array}$ & $\begin{array}{l}\text { Microtallos con } \\
\text { callo basal (\%) }\end{array}$ & $\begin{array}{l}\text { Microtallos } \\
\text { enraizados (\%) }\end{array}$ \\
\hline T1 & MS & $3,2(\mathrm{~b})$ & $4(\mathrm{c})$ & $100(\mathrm{a})$ & $13,3(\mathrm{~b})$ \\
T2 & B5 & $2,2(\mathrm{a})$ & $1,4(\mathrm{a})$ & $20(\mathrm{~b})$ & $95(\mathrm{a})$ \\
T3 & Wh & $3,4(\mathrm{bc})$ & $2,8(\mathrm{~b})$ & $95(\mathrm{a})$ & $90(\mathrm{a})$ \\
T4 & WPM & $3(\mathrm{ab})$ & $2,6(\mathrm{~b})$ & $90(\mathrm{a})$ & $85(\mathrm{a})$ \\
T5 & A & $4,4(\mathrm{~d})$ & $2,6(\mathrm{~b})$ & $95(\mathrm{a})$ & $95(\mathrm{a})$ \\
T6 & AT & $3(\mathrm{~b})$ & $2,6(\mathrm{~b})$ & $85(\mathrm{a})$ & $90(\mathrm{a})$ \\
T7 & H & $5,1(\mathrm{~d})$ & $4(\mathrm{c})$ & $11,4(\mathrm{~b})$ & $100(\mathrm{a})$ \\
T8 & H-2\% Saca- & $4,3(\mathrm{~cd})$ & $4,2(\mathrm{c})$ & $3(\mathrm{~b})$ & $100(\mathrm{a})$ \\
& rosa & & & & \\
\hline
\end{tabular}

capaces de soportar el estrés producido por las condiciones propias del endurecimiento. Después de 60 días de aclimatización en invernadero las plántulas presentaron una apariencia vigorosa con crecimiento y desarrollo de hojas y yemas axilares, características adecuadas para ser utilizados como portainjerto de lulo de castilla.

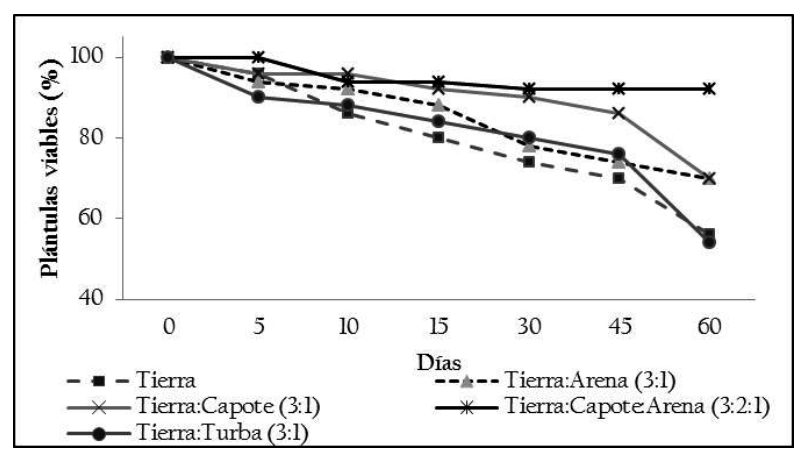

Figura 4. Viabilidad de plántulas de S. dolichosepalum durante 60 días de aclimatización.

\section{Conclusiones}

Se estableció un protocolo de micropropagación de $S$. dolichosepalum a partir de semillas cultivadas en MS/4, previamente esterilizadas con $\mathrm{NaOCl}$ al
$10 \%$ (v/v) durante 15 minutos. La multiplicación de microtallos a través de segmentos nodales se realizó adecuadamente en medio $\mathrm{H}$ con $2 \%$ de sacarosa, suplementado con $0,02 \mathrm{mg} \mathrm{L}^{-1}$ de ANA y $0,02 \mathrm{mg}$ $\mathrm{L}^{-1}$ de BA. Después de 30 días de cultivo los microtallos alcanzaron en promedio $4 \mathrm{~cm}$ de longitud con 4 yemas axilares; el enraizamiento de microtallos alcanzó $100 \%$ y fue simultáneo con la fase de multiplicación. La aclimatización en invernadero, utilizando como sustrato una mezcla de tierra, capote y arena, 3:2:1, permitió recuperar $100 \%$ de plántulas viables. Después que se ratifique el grado de tolerancia de $S$. dolichosepalum a Fusarium oxysporum, este protocolo, que es el primero para la especie, permitirá producir masivamente material injertado de lulo de castilla para el establecimiento de huertos comerciales.

\section{Agradecimientos}

A los integrantes del Grupo de Investigación BIOPLASMA-UPTC por la colaboración recibida durante el desarrollo de esta investigación, así como a la Dirección de Investigaciones, DIN, de la Uni- 
versidad Pedagógica y Tecnológica de Colombia por los recursos económicos otorgados para tal fin.

\section{Referencias}

[1] S. Padulosi, P. Eyzaquirre y T. Hodgkin. "Challenges and strategies in promoting conservation and use of neglected and underutilized crop species". In. Perspectives on new crops and new uses. J. Janick, Ed. ASHS Press, Alexandria, U.S.A., pp. 140-145, 1999.

[2] X. Scheldeman, W. Rojas, R. Valdivia, V. Peralta, E. Peralta y S. Padulosi. "retos y posibilidades del uso de especies olvidadas y subutilizadas en un desarrollo sostenible". 2003; 8 pp. Disponible en: https://www.researchgate.net/profile/Xavier _Scheldeman/publication/255601559_Retos_y _Posibilidades_del_Uso_de_Especies_Olvi dadas_y_Subutilizadas_en_un_Desarrollo_Sos tenible/links/00b7d53b54f8f66daa000000.pdf

[3] O. Sepulveda, Z. Suárez, M. Patarroyo, L. Canaria y S. Bautista, "Estudio del comportamiento e impacto de la climatología sobre el cultivo de la papa y del paso en la región central de Boyacá empleando los sistemas dinámicos". Ciencia en Desarrollo, vol. 6, no. 2, pp. 215224, 2015.

[4] A. Lane. "Una introducción a los parientes silvestres de cultivos". In R. D. Raymond. Parientes silvestres de cultivos. OBioversity International. Roma, Italia, pp. 1-2, 2006.

[5] E. Barrios Paternina, J. Mercado Gómez, "Plantas útiles del corregimiento Santa Inés y la vereda San Felipe (San Marcos, Sucre, Colombia)". Ciencia en Desarrollo, vol. 5, no. 2, pp. 131144, 2014.

[6] M.R. González y C.R. López. "Catálogo de las plantas vasculares de Ráquira (Boyacá), flora andina en un enclave seco de Colombia". Colombia Forestal, vol. 15, n ${ }^{\circ}$ 1, pp. 55-103, 2012.

[7] M.F. Restrepo, L. Álvarez, J.H. Gallego. "Solanaceae". En: Centro de Investigaciones y Desarrollo Científico Universidad de Caldas, Banco de la República Ed. Uso popular de las plantas medicinales en tres zonas de Caldas: Manizales, Riosucio y Viterbo. (En offset), pp. 270, 1990.
[8] M. Arango, J.G. Bueno, G. Isaza, J.E. Pérez, L.F. Álvarez, E.J. Osorio, A.J. Rincón y A.C. Duque "Efectos antibacterianos y antimicóticos de Alternathera williamsii, Solanum dolichosepalum, Baccharis trinervis, Tabebuia chrysantha y Phenax rugosus". Biosalud, vol. 3, pp. 49-55, 2004.

[9] S.B. Pimentel y M.E. Reynolds. "Candidiasis Vaginal". Rev Paceña Med Fam, vol. 4, no. 6, pp. 121-127, Junio, 2007.

[10] J.E. Pérez, G. Isaza, J.G. Bueno, M.C. Arango, B.L. Hincapié, A.M. Nieto y D.P. Londoño. "Efecto de los extractos de Phenax rugosus, Tabebuia chrysantha, Alternantera williamsi y Solanum dolichosepalum sobre el leucograma y la producción de anticuerpos en ratas". Rev. Med. Risaralda, vol. 10, no. 2, pp. 13-21, Noviembre, 2004.

[11] M.A. Ocampo, Z.C. López, C.J. Pérez y G. Mejía. "Actividad antifúngica de los extractos acuosos de Baccharis trinervis, Baccharis latifolia y Solanum dolichosepalum”. Biosalud, vol. 5, pp. 51-59, Octubre, 2006.

[12] Manejo fitosanitario del cultivo del lulo (Solanum quitoense Lam)- Medidas para la temporada invernal. Instituto Colombiano Agropecuario-ICA. Produmedios, Bogotá D.C. Colombia, 2011.

[13] H. Hartamann, D. Kester, D. Davies y R. Geneve. 1992. "Plant propagation principles and practices. $8^{\circ}$ Edición. Mexico, 1992.

[14] "Producción comercial de lulo (Solanum quitoense Lam.) injertado sobre el patrón de friegaplatos (Solanum torvum)". Fundación Hondureña de Investigación Agrícola - FHIA. La Lima, Cortés. Hoja técnica No. 7, p. 2, Noviembre, 2009.

[15] D.P. Viteri, C.W. Vásquez, F.J. León, W. Viera, M. Posso, A.M. Hinojosa, J. Revelo y J. Ochoa. "Naranjilla de jugo mejorada (Solanum quitoense Lam.) injertada en patrones de solanáceas silvestres resistentes a Fusarium oxysporum y Meloidogyne incognita." Instituto Nacional de investigaciones agropecuarias. Estación experimental Santa Catlina, Quito, Ecuador. Boletín divulgativo No. 354, Junio, 2009.

[16] M.S. Mitidieri, M.V. Brambilla, M. Piris, E. Piris y L. Maldonado. "El uso de portainjertos 
resistentes en cultivo de tomate bajo cubierta: resultados sobre la sanidad y el rendimiento del cultivo". INTA Centro Regional Buenos Aires Norte, Buenos Aires, Argentina. Disponible en: http://www.biblioteca.org.ar/libros/210791.pdf

[17] Q. M. Arizala, P.A. Monsalvo, G.C. Betancourth, G.C. Salazar y B.T. Lagos. "Evaluación de solanáceas silvestres como patrones de lulo (Solanum quitoense Lam) y su reacción a $\mathrm{Fu}$ sarium Sp." Revista de Ciencias Agrícolas, vol, 28 no. 1, pp. 147-160, 2011.

[18] A. Pina. "Caracterización fisiológica y bioquímica de las respuestas que intervienen en la incompatibilidad de injerto en albaricoquero (Prunus armeniaca L.)". Tesis Doctoral. Centro de Investigación y Tecnología Agroalimentaria de Aragón (CITA). Zaragoza, 2006.

[19] D.L. Criollo "Evaluación de dos técnicas para la microinjertación de Babaco (Vasconcella heibornii cv. Pentagona) y Chihualcan (Vasconcella heibornii cv. crysopetala) en patrones de papaya (Carica papaya) bajo condiciones de laboratorio". Trabajo fin de carrera Ingeniería en Biotecnología Departamento de Ciencias de la Vida. Escuela Politécnica del Ejército, Santa Catalina-INIAP., Sangolquí-Ecuador, 2008.

[20] M.J. Bolívar y A.D. Tovar. "Micropropagación, selección y ensayos preliminares in vitro de tolerancia a salinidad y toxicidad por aluminio de materiales de mora (Rubus glaucus B.) y lulo (Solanum quitoense L.) cultivados en los altiplanos de Boyacá". Tesis de Pregrado. Escuela de Biología Facultad de Ciencias. Universidad Pedagógica y Tecnológica de Colombia-UPTC, Tunja, Boyacá, 2001.

[21] T. Murashige y F. Skoog, "Arevised médium for rapid growth and bioassays for tobacco tissue culture". Physiol Plant, vol. 15, pp. 473497, Abril, 1962.

[22] O.L. Gamborg, R.A. Miller y K. Ojima, "Nutrient requirements of suspension cultures of soybean root cells". Exp Cell Res, vol. 50, pp. 151-158, Junio, 1968.

[23] M. Singh y A.D. Krikorian. "White's standard nutrient solution". Ann. Bot., vol. 47, pp. 133139, Junio, 1981.

[24] G. Lloyd y McC. Brent. "Commercially feasible micropropagation of mountain laurel, $\mathrm{Kal}$ - mia latifolia, by use of shoot-tip culture”. Proceedings International Plant Propagatorst' Society, vol. 30, pp. 421-427, Octubre, 1980.

[25] G. Hussey y N.J. Stacey. "In vitro propagation of potato (Solanum tuberosum L.)”. Ann. Bot., vol. 48, pp. 787-796, Marzo, 1981.

[26] R. Atkinson y R. Gardner. "Regeneration of transgenic tamarillo plants". Plant Cell Rep., vol. 12, pp. 347-351, Enero, 1993.

[27] R. Hendrix, R. Litz y B. Kirchoff. "In vitro organogenesis and plant regeneration from leaves of Solanum candidum, S. quitoense (naranjilla) and S. sessiliflorum". Plant Cell Tissue Organ Culture, vol. 11, pp. 67-73, Junio, 1987.

[28] Contreras y J. Almeida. "Micropropagación del tomatillo (Physalis ixocarpa L.)". Rev. Fac. Farm., vol. 45, no. 1, pp. 61-64. Junio, 2003.

[29] L. Rache, M. J. Pacheco, "Establecimiento de un protocolo de propagación de Physalis peruviana L. a partir de yemas axilares adultas". Ciencia en Desarrollo, vol. 4, no. 1, pp. 78-85, 2012.

[30] W. Roca y L. Mroginski. "Cultivo de tejidos en la agricultura: Fundamentos y Aplicaciones". CIAT (Centro Internacional de Agricultura Tropical). Ed Cali. Colombia, 1991.

[31] S. Olmos, G. Luciani y E. Galdeano. "Parte V Métodos de propagación y conservación de germoplasma. Micropropagación”. In: Biotecnología y Mejoramiento Vegetal II. G. Levitus, V. Echenique, C. Rubinstein, E. Hopps y L. Mroginski. Ediciones Instituto Nacional de Tecnología Agropecuaria, Argentina, pp. 161172, 2004.

[32] D. Andrade-Díaz, M. Córdoba-Figueroa, H. Criollo-Escobar y T. Lagos-Burbano. "Evaluación de medios de cultivo para propagación in vitro de semillas y explantes de especies silvestres de Solanum". Acta Agronómica, vol. 62, no. 1, pp. 27-36. Septiembre, 2013.

[33] C.C. Moreno. "Efecto de ácido giberélico (Ag3), nitrato de potasio (KNO3) y rizobacterias promotoras del crecimiento vegetal (PGPRs), sobre el desarrollo temprano de Solanum sessiliflorum (cocona)". Tesis de pregrado. Programa de Biología Aplicada Facultad de Ciencias Básicas Universidad Militar Nueva Granada. Bogotá D.C., Colombia, 2012. 
[34] O.M. Suárez-Cardoso, E.T. Naranjo-Gómez, L. Atehortúa-Garcés, y S. Blair-T. "Organogénesis directa in vitro a partir de hojas de la planta Antiplasmodial Solanum nudum Dunal". Revista Colombiana de Biotecnología, vol. 3 no. 2, pp. 186-192, Noviembre, 2011.

[35] W. Cárdenas, M. L. Zuluaga y M. Lobo. "Latencia en semillas de lulo (Solanum quitoense Lam.) y tomate de árbol (Cyphomandra betacea (Solanum betaceum) Cav. Sendt) como aspecto básico para la conservación y el monitoreo de viabilidad de las colecciones". Plant Genet. Res. Newsl., vol. 139 pp. 31-41, Junio, 2004.

[36] G. del C. Rivero- Maldonado, M. del C. Ramirez-Villalobos y S. León de Sierralta. "Tipo de explante en el establecimiento in vitro del guanábano (Annona muricata L.)" Rev. fac. Agron., vol. 18, pp. 258-265, Julio, 2001.

[37] D.T. Nhut, J.A. Teixeira da silva y C.R. Aswath. "The importance of the explant on regeneration in thin cell layer technology". In Vitro Cell. Dev. Biol.-Plant, vol. 39, pp. 266-276, Junio, 2003.

[38] M. Pirela y N. Mogollón. "In vitro clonal propagation of guava (Psidium guajava L.) cv. Mara7 from stem shoots of cv. Mara-7". Acta Horticulturae, vol. 452 pp. 47-52, Junio, 1996.

[39] Puddephat, P. Alderson y N. Wright. Ïnfluence of explant source, plant growth regulators and culture environment on culture initiation and establishment of Quercus robur L. in vitro". J. Exp. Bot., vol. 48, pp. 951-962, Noviembre, 1997.

[40] P. Dublin. "Multiplicación vegetativa de café, hevea y cacao." In: Cultivo de tejidos en la Agricultura: Fundamentos y aplicaciones. W. Roca y L. Mroginski, Ed. Centro Internacional de Agricultura Tropical- CIAT. Cali, Colombia, pp. 969, 1991.

[41] G. A. Medina. "Conocimiento tradicional y cultivo in vitro de Cuatomate (Solanum glaucescens Zucc)". Tesis Maestría en Ciencias. Colegio de postgraduados- Institución de Enseñanza e Investigación en Ciencias Agrarias. Puebla, México, 2011.

[42] P. Robledo y C. Carrillo "Regeneración in vitro de plantas de Chile (Capsicum annuum L.) mediante cultivo de cotiledones e hipocótilos". Rev. Fitotec. Mex., vol. 27, pp.121-126, Junio, 2004.

[43] R. Chacón-Cerdas, D. Flores-Mora, L. Alvarado-Marchena, A. Schmidt-Durán y C. Alvarado-Ulloa. "Cultivo in vitro del tomate de árbol (Cyphomandra betacea (Cav.) Sendt. (Fenotipo naranja) proveniente de Costa Rica". Tecnología en Marcha, pp. 45-55. Junio, 2014. Disponible en: http://revistas.tec.ac.cr/index.php/tec_marcha/ article/view/2014. doi: http://dx.doi.org/ $10.18845 / \mathrm{tm} . v 27 \mathrm{i} 0.2014$.

[44] A. O'Connor-Sánchez, A. Domínguez-May, M. Keb-Llanes, Y. Peña-Ramírez y V. HerreraValencia. "Regeneración de plantas de Mullein Nightshade (Solanum donianum Walp.) a partir de explantes de hoja". Phyton (B. Aires), vol. 79, no. 1, pp. 25-29,. Junio, 2010.

[45] M.J. Apraez, D.J. Romo y T.C. Lagos. "Regeneración de plantas de tomate de árbol (Cyphomandra betacea Cav. Sendt.) mediante organogénesis inducida a partir de callos". Revista de Ciencias Agrícolas, vol. 29, no. 2, pp. 108-115, Noviembre, 2012.

[46] E.F. George, M.A. Hall y G.J. Klerk. Plant Propagation by Tissue Culture. Springer, Basingstoke, UK, 2008.

[47] P. Rosati, G. Marion y C. Swierczwski. "In vitro propagation of Japanese plum (Prunus salicina Lindi. cv. calita)". J Amer Soc Hort Sci. vol. 105, pp. 126-29. Noviembre, 1980.

[48] O. Theander y D.A. Nelson D.A. Aqueous, high temperature transformation of carbohydrates relative to utilization of biomass. $A d v$ Carbohydr Chem Biochem, vol. 46, pp. 273326. Junio, 1988.

[49] J.B. Teixeria, M.R. Sondahl y E.G. Kirby. "Somatic embryogenesis from immature inflorescences of oil palm". Plant Cell Rep., vol. 13, pp. 247-250, Febrero, 1994.

[50] H.R. Owen, D. Wengerd y A. R. Miller. "Culture medium $\mathrm{pH}$ is influenced by basal medium, carbohydrate source, gelling agent, activated charcoal, and medium storage method." Plant Cell Rep., vol. 10, pp.583-586. Diciembre, 1991. 
[51] E. Dumas y O. Monteuuis. "In vitro rooting of micropropagated shoots from juvenile and mature Pinus pinaster explants-influence of activated charcoal". Plant Cell Tissue Organ Cult., vol. 40, pp. 231-235, Marzo, 1995.

[52] M. Borges y Y. Sosa. "Efectos de la adición de diferentes concentraciones de carbón activado sobre la multiplicación in vitro de ñame". Biotecnología Vegetal. vol. 8, no. 2, pp. 87-90, Junio, 2008.

[53] B. Assy-Bah y F. Engelmann. "Medium-term conservation of mature embryos of coconut". Plant Cell Tissue Organ Cult. vol. 33, no.3, pp. 19-24, Abril, 1993.

[54] V. Dos Santos. "Regeneraçao in vitro de embrioes de Cocos nucifera L". Tesis de Maestría en Ciencias. Piracicaba, Sao Paulo, Brasil, 2002.

[55] Z. Lentini, J. Ruiz, V. Segovia, E. Tabares y F. Hincapie. "Propagación in vitro y regeneración de plantas de lulo (Solanum quitoense) y su uso como clones élites por agricultores".
Centro Internacional de Agricultura Tropical (CIAT), Cali, 2004.

[56] A.D. Krikorian. "Medios de cultivo: Generalidades, composición y preparación" in Cultivo de tejidos en la Agricultura: Fundamentos y aplicaciones, W. Roca y L. Mroginski Ed. Centro Internacional de Agricultura TropicalCIAT. Cali, Colombia. 1991, 969 pp.

[57] A. M. Duarte, K. M. Núñez, J. C. Pacheco, J. J. Martínez, "Compuestos volátiles producidos in vitro por callos de Solanum quitoense Lam. (Solanaceae)", Ciencia en Desarrollo, vol. 5, no. 1, pp. 49-54, 2014.

[58] F. López, N. Guío, G. Fischer y D. Mirando. "Propagación de uchuva (Physalis peruviana) mediante diferentes tipos de esquejes y sustratos", Rev. Fac. Nal. Agr. Medellín, vol. 61, no. 1, pp. 4347 4357, Junio, 2008.

[59] D. Díaz, D. González, L. Rache y J. Pacheco. "Efecto citogenético de la colchicina sobre yemas vegetativas de Physalis peruviana L.", Prospec. Cient. vol. 4, pp. 27-40, Noviembre, 2008. 